\title{
Overcoming Clinical Inertia: A Randomized Clinical Trial of a Telehealth Remote Monitoring Intervention Using Paired Glucose Testing in Adults With Type 2 Diabetes
}

Deborah A Greenwood ${ }^{1,2}$, RN, PhD; Shelley A Blozis ${ }^{3}, \mathrm{PhD}$; Heather M Young ${ }^{4}$, RN, PhD, FAAN; Thomas S Nesbitt ${ }^{5}$, MD, MPH; Charlene C Quinn ${ }^{6}$, RN, PhD, FAAN

\footnotetext{
${ }^{1}$ Clinical Performance Improvement Consultant, Office of Patient Experience, Quality and Clinical Effectiveness, Sutter Health, Sacramento, CA, United States

${ }^{2}$ Program Coordinator, Sutter Health Integrated Diabetes Education Network, Sutter Medical Foundation, Sacramento, CA, United States

${ }^{3}$ Associate Professor, Department of Psychology, University of California Davis, Davis, CA, United States

${ }^{4}$ Associate Vice Chancellor for Nursing, Dean and Professor, Betty Irene Moore School of Nursing, University of California Davis, Sacramento, CA, United States

${ }^{5}$ Associate Vice Chancellor, Strategic Technologies and Alliances, Director, Center for Health and Technology, University of California Health System, Sacramento, CA, United States

${ }^{6}$ Associate Professor, Department of Epidemiology and Public Health, School of Medicine, Univeristy of Maryland, Baltimore, MD, United States
}

\section{Corresponding Author:}

Deborah A Greenwood, RN, PhD

Clinical Performance Improvement Consultant

Office of Patient Experience, Quality and Clinical Effectiveness

Sutter Health

2200 River Plaza Drive

Sacramento, CA, 95833

United States

Phone: 19167124597

Fax: 19165037596

Email: greenwd@sutterhealth.org

\begin{abstract}
Background: Type 2 diabetes mellitus is a worldwide challenge. Practice guidelines promote structured self-monitoring of blood glucose (SMBG) for informing health care providers about glycemic control and providing patient feedback to increase knowledge, self-efficacy, and behavior change. Paired glucose testing — pairs of glucose results obtained before and after a meal or physical activity —is a method of structured SMBG. However, frequent access to glucose data to interpret values and recommend actions is challenging. A complete feedback loop—data collection and interpretation combined with feedback to modify treatment—has been associated with improved outcomes, yet there remains limited integration of SMBG feedback in diabetes management. Incorporating telehealth remote monitoring and asynchronous electronic health record (EHR) feedback from certified diabetes educators (CDEs) — specialists in glucose pattern management—employ the complete feedback loop to improve outcomes.

Objective: The purpose of this study was to evaluate a telehealth remote monitoring intervention using paired glucose testing and asynchronous data analysis in adults with type 2 diabetes. The primary aim was change in glycated hemoglobin $\left(\mathrm{A}_{1 \mathrm{c}}\right)-\mathrm{a}$ measure of overall glucose management-between groups after 6 months. The secondary aims were change in self-reported Summary of Diabetes Self-Care Activities (SDSCA), Diabetes Empowerment Scale, and Diabetes Knowledge Test.

Methods: A 2-group randomized clinical trial was conducted comparing usual care to telehealth remote monitoring with paired glucose testing and asynchronous virtual visits. Participants were aged 30-70 years, not using insulin with $\mathrm{A}_{1 \mathrm{c}}$ levels between $7.5 \%$ and $10.9 \%(58-96 \mathrm{mmol} / \mathrm{mol})$. The telehealth remote monitoring tablet computer transmitted glucose data and facilitated a complete feedback loop to educate participants, analyze actionable glucose data, and provide feedback. Data from paired glucose testing were analyzed asynchronously using computer-assisted pattern analysis and were shared with patients via the EHR weekly. CDEs called participants monthly to discuss paired glucose testing trends and treatment changes. Separate mixed-effects models were used to analyze data.
\end{abstract}


Results: Participants (N=90) were primarily white $(64 \%, 56 / 87)$, mean age 58 (SD 11) years, mean body mass index 34.1 (SD 6.7) $\mathrm{kg} / \mathrm{m} 2$, with diabetes for mean 8.2 (SD 5.4) years, and a mean $\mathrm{A}_{1 \mathrm{c}}$ of $8.3 \%$ (SD 1.1; $67 \mathrm{mmol} / \mathrm{mol}$ ). Both groups lowered $\mathrm{A}_{1 \mathrm{c}}$ with an estimated average decrease of 0.70 percentage points in usual care group and 1.11 percentage points in the treatment group with a significant difference of 0.41 percentage points at 6 months ( $\left.\mathrm{SE} 0.08, \mathrm{t}_{159}=-2.87, P=.005\right)$. Change in medication $\left(\mathrm{SE} 0.21, \mathrm{t}_{157}=-3.37, P=.009\right)$ was significantly associated with lower $\mathrm{A}_{1 \mathrm{c}}$ level. The treatment group significantly improved on the SDSCA subscales carbohydrate spacing $(P=.04)$, monitoring glucose $(P=.001)$, and foot care $(P=.02)$.

Conclusions: An eHealth model incorporating a complete feedback loop with telehealth remote monitoring and paired glucose testing with asynchronous data analysis significantly improved $\mathrm{A}_{1 \mathrm{c}}$ levels compared to usual care.

Trial Registration: Clinicaltrials.gov NCT01715649; https://www.clinicaltrials.gov/ct2/show/NCT01715649 (Archived by WebCite at http://www.webcitation.org/6ZinL18D0).

(J Med Internet Res 2015;17(7):e178) doi: 10.2196/jmir.4112

\section{KEYWORDS}

telehealth; remote consultation; electronic health records; health records, personal; diabetes mellitus, type 2; self-care; monitoring, physiologic; blood glucose self-monitoring; hemoglobin A1c, glycosylated; eHealth; patient participation

\section{Introduction}

In the United States, 9.3\% of Americans have diabetes mellitus; of those, $90 \%$ to $95 \%$ are diagnosed with type 2 diabetes [1]. When uncontrolled, diabetes is the seventh leading cause of death and the leading cause of kidney failure, blindness, and nontraumatic amputations in the United States [1]. Achieving national diabetes outcome targets for blood glucose, blood pressure, and blood fats can decrease complications and improve quality of life [2]. However, research indicates people with diabetes remain at suboptimal glucose control for 2.9 years from patient and provider clinical inertia limiting treatment intensification $[3,4]$. Self-management of diabetes is a critical component of diabetes care [2] and self-monitoring of blood glucose (SMBG) is an essential self-management behavior [2,5]. Evaluation of SMBG data by primary care providers encourages more frequent medication changes and several studies indicate improved glycemic control [6-8]. Practice guidelines promote the use of SMBG for informing health care providers about glycemic control and providing patient feedback to increase knowledge, self-efficacy, and behavior change [9-11]. Effective SMBG includes structured behaviors such as (1) frequency of glucose testing, (2) participant use and response to glucose data, (3) health care provider data interpretation, and (4) therapy modifications $[12,13]$. However, there is controversy regarding the benefit of SMBG to improve glycated hemoglobin $\left(\mathrm{A}_{1 \mathrm{c}}\right)_{-} \mathrm{a}$ measure of overall blood glucose control-in persons with noninsulin-treated type 2 diabetes with some systematic reviews reporting no reduction in $\mathrm{A}_{1 \mathrm{c}}[14,15]$. However, current research incorporating structured monitoring profiles-defining the frequency, intensity, and timing of SMBG-shows significant improvement in $\mathrm{A}_{1 \mathrm{c}}[6,7,16,17]$. Although there is limited research to document the most effective SMBG profile, paired glucose testing (eg, pairs of glucose results obtained before and after a meal, physical activity, or other event) is one suggested profile $[10,18]$. However, it is challenging to access glucose data frequently to interpret values and recommend patient actions.

A complete feedback loop-data collection and interpretation combined with feedback to the patient to modify treatment plan-has been associated with improved outcomes [19]. Although the complete feedback loop is an essential component of both SMBG [20] and remote monitoring, there is limited and inconsistent incorporation of SMBG feedback in diabetes management [14,19-21]. Although research has evaluated telehealth remote monitoring glucose data, few studies have incorporated SMBG profiles that provide timely feedback to patients and allow for real-time decision making [22].

In primary care, health care providers are often not prepared to interpret SMBG data, respond to patterns, and implement a complete feedback loop with tailored feedback for behavior change or treatment modifications [14,23]. Diabetes management programs with nurse care coordination [14,23] often include diabetes education provided by certified diabetes educators (CDEs), who are uniquely qualified to analyze SMBG data and problem solve with patients. Incorporating telehealth remote monitoring with $\mathrm{CDE}$ support employs the complete feedback loop to improve outcomes. Figure 1 shows the complete feedback loop elements [19]. The patient generates glucose data following targeted education on the elements of structured SMBG. Next, data are analyzed and synthesized by both the CDE and the patient using pattern management and evidence-based guidelines. In collaboration, the CDE and patient agree on modification of the existing treatment plan through active communication and tailored feedback from the CDE. Finally, a new action plan is developed using shared decision making and implemented by the patient and the cycle continues.

Telehealth remote monitoring may improve clinical outcomes, care coordination, engagement, and satisfaction [24,25]. Novel clinical interventions are needed that expand existing paradigms of diabetes care by utilizing telehealth remote monitoring and actionable patient-generated data for timely behavior and treatment changes. The purpose of this study was to test the effectiveness of a telehealth remote monitoring intervention with paired glucose testing for adults with noninsulin-treated type 2 diabetes. The hypothesis was that the intervention would result in a greater change in $\mathrm{A}_{1 \mathrm{c}}$ and improved self-management, self-efficacy, and diabetes knowledge compared to usual care over 6 months. 
Figure 1. Complete feedback loop for improved outcomes in diabetes management.

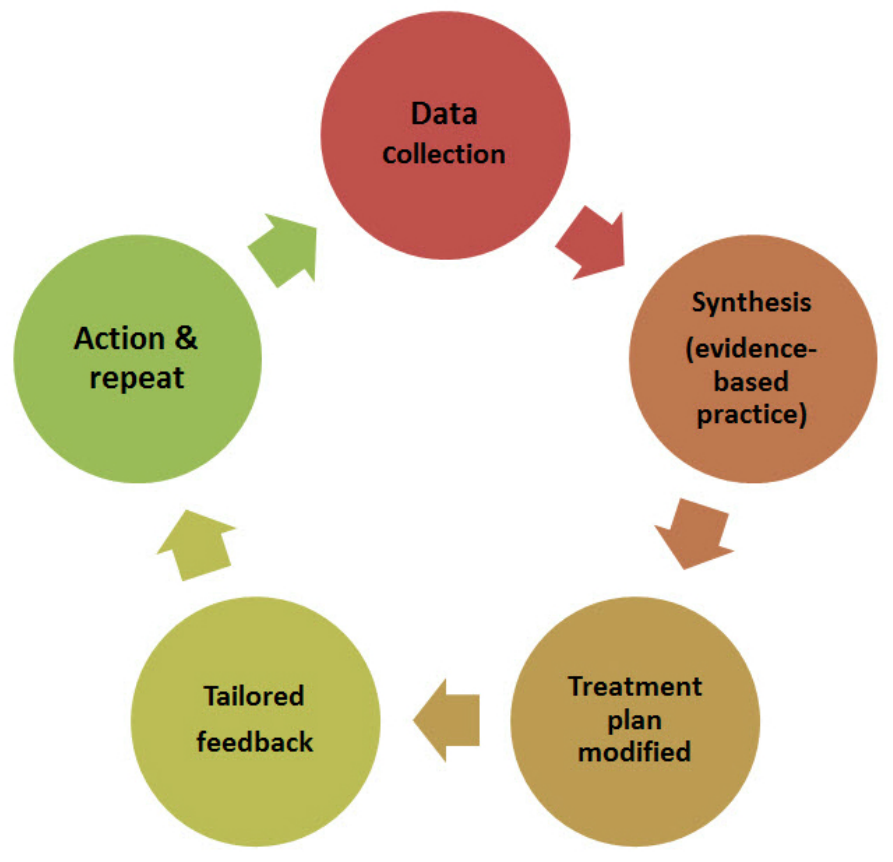

\section{Methods}

\section{Study Design}

The study was a 2-group randomized clinical trial with 1:1 randomization to usual care or telehealth remote monitoring with paired glucose testing (treatment group). Sample size was determined based on the main outcome: mean change in $A_{1 c}$ between treatment and usual care over 6 months. The comparison of usual care $(n=39)$ to treatment participants $(n=39)$ had $80 \%$ power to detect a $0.9 \%$ difference in $\mathrm{A}_{1 \mathrm{c}}$ between treatment and usual care after 6 months ( $\alpha=.05,2$-tailed). A $15 \%$ additional margin for participant dropout resulted in a sample size of $n=45$ per group.

\section{Setting}

The study was conducted between January and October 2013 in a large health care system in California with an established diabetes management program with telephonic nurse care coordination for diabetes population health management. CDEs proactively telephoned patients with $\mathrm{A}_{1 \mathrm{c}} \geq 10 \%(86 \mathrm{mmol} / \mathrm{mol})$ to develop care plans, whereas patients in lower risk groups $\left(\mathrm{A}_{1 \mathrm{c}} 7.5 \%-9 \%\right.$ or $58-75 \mathrm{mmol} / \mathrm{mol}$ ) called the program if desired. CDEs were trained in motivational interviewing to support behavior change, structured paired glucose testing, pattern management, and medication management. Approximately 7000 patients were enrolled in the diabetes management program at that time and nearly 1500 patients met the inclusion criteria.

\section{Recruitment and Enrollment}

Participants were recruited through query of the electronic health record (EHR) and diabetes management database using the International Classification of Diseases, Ninth Revision (ICD-9) code 250.02. The inclusion criteria were:
1. Type 2 diabetes diagnosis treated with oral antihyperglycemic medications, noninsulin injectable medications, or lifestyle alone;

2. Participant in the diabetes management program for previous 12 months;

3. Aged between 30 and 70 years;

4. $\mathrm{A}_{1 \mathrm{c}}$ between $7.5 \%$ and $10.9 \%(58-96 \mathrm{mmol} / \mathrm{mol})$ in previous 6 months;

5. Internet or $3 \mathrm{G}$ connection with email access;

6. Landline or cellular phone;

7. English speaking; and

8. Primary care provider in health system.

Exclusion criteria identified by medical chart review included:

1. Insulin prescription;

2. Unable to independently self-manage (diagnosis of dementia, severe depression, schizophrenia, or cognitive impairment for previous 12 months); and/or

3. Diagnoses of debilitating stroke, heart failure, end-stage renal disease, or legally blind.

Eligible participants were contacted through mail, email, and telephone (see Figure 2). Consent forms were mailed and emailed to participants. The research team obtained informed consent by telephone and then participants signed consents and returned by postal mail. We estimated a $15 \%$ enrollment rate, but $6 \%$ was attained. Major reasons for ineligibility were non-English speakers $(21 \%, 8 / 37)$, insulin $(21 \%, 8 / 37)$, primary care provider not in health system $(16 \%, 6 / 37)$, and no Internet access $(14 \%, 5 / 37)$.

A permuted block, with blocks of 4 and 6 , and a computer-generated random number table were utilized for randomization. After participants signed the consent form, the research coordinator assigned sequential study identification (ID) numbers. The investigator matched the ID numbers to the random number table to assign study group. Participants were 
notified of group assignment by email after completing online baseline self-assessment questionnaires. Participants randomized to the control group (usual care) were informed to continue in the diabetes management program for usual care. Blinding of participants, providers, and the research team was not possible.

Participants in both groups received a US $\$ 10$ gift card after completing online questionnaires. $\mathrm{A}_{1 \mathrm{c}}$ tests were ordered every

Figure 2. CONSORT flowchart of enrollment and participant status.
3 months, as is standard of care when $\mathrm{A}_{1 \mathrm{c}}$ is elevated, then billed to insurance. $A_{1 c}$ tests were collected at health system laboratories using similar equipment following standardized procedures. Questionnaires were completed online using the Research Electronic Data Capture (REDCap) database. The study was approved by Sutter Health Central Institutional Review Committee and a Data and Safety Monitoring Board (DSMB) reviewed the study procedures and adverse events.

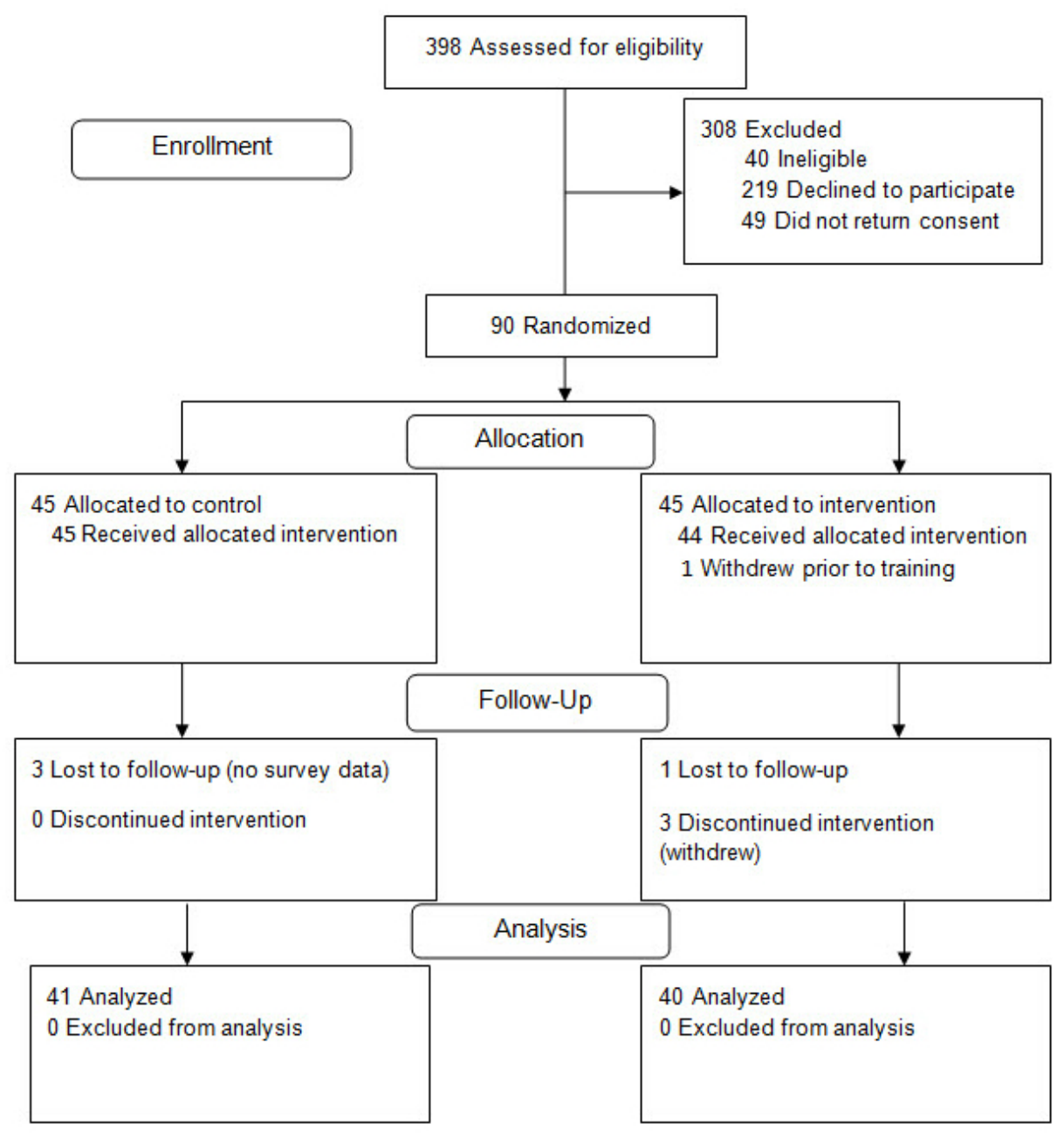

\section{Measures}

\section{Primary Outcome}

The primary outcome was the difference in mean change in $A_{1 c}$ from baseline to 6 months between groups. $A_{1 c}$ at recruitment (prestudy $\mathrm{A}_{1 \mathrm{c}}$ ), baseline, and 3 and 6 months postprogram was obtained from EHR review. Baseline data were the most recent $A_{1 \mathrm{c}}$ recorded before study enrollment in the previous 6 months. At the conclusion of the study, the $\mathrm{A}_{1 \mathrm{c}}$ was scheduled within a 3 -month time period, approximately 4 weeks before and 8 weeks after the 6-month due date.

\section{Secondary Outcomes}

\section{Diabetes Knowledge}

Diabetes knowledge was measured using the Diabetes Knowledge Test (DKT) [26], a valid and reliable measure for estimating general understanding of diabetes, including healthy eating and glucose monitoring consisting of 23 multiple-choice items. The first 14 items, appropriate for people not using insulin, were administered to study participants. Scores are measured as the number of correct answers divided by the possible total of 14 .

\section{Self-Management}

Self-management was measured by the Summary of Diabetes Self-Care Activities (SDSCA) [27], a 12-item self-report questionnaire with subscales: general diet, specific diet, carbohydrate spacing, exercise, monitoring blood glucose, and foot care. For example, participants were asked: "In how many of the past 7 days (0-7) did you check your blood glucose?" Higher scores indicate better self-care behavior. 


\section{Self-Efficacy}

Self-efficacy was measured by the Diabetes Empowerment Scale short form (DES-SF), an 8-item measure of psychosocial self-efficacy in people with diabetes [28]. Scores ranged from $1-5$, with 5 indicating "strongly agree." The mean score of 8 items is reported.

\section{Usual Care/Control Group}

Participants in usual care received diabetes education booklets and referral for formal diabetes education as needed. This group continued to receive nurse care coordination including reminders for $\mathrm{A}_{1 \mathrm{c}}$ and health maintenance exams sent by postal mail. The CDEs evaluated SMBG data when reported by participants (no specific monitoring profile was required) and discussed behavior changes with participants by telephone and/or secure messaging and discussed possible medication changes with their primary care provider through the EHR staff messaging tool. CDE contact with the usual care group was documented in the study database.

\section{Treatment Group: Structured Glucose Monitoring}

The intervention incorporated a complete feedback loop and all essential elements of structured monitoring. Before the intervention, $6 \mathrm{CDEs}$ attended in-person training sessions on intervention procedures, paired testing, and the goal of implementing a complete feedback loop. Participants in the treatment group attended a 1-hour, small group, in-person training session led by the CDE that included (1) use of the glucose meter, (2) implementation of the complete feedback loop, (3) use of paired glucose testing (frequency and intensity of monitoring), (4) American Diabetes Association (ADA) goals for pre- and postmeal, (5) how to use SMBG data to modify behavior or treatment, (6) expected feedback from CDEs with communication by secure message or phone, and (7) the use of shared decision making to implement the treatment plan [22]. Participants created a "personal experiment" and agreed to check glucose before and 2 hours after the same meal or physical activity for 1 week, and created a behavior change action plan to evaluate changes in SMBG data.

During training, participants were educated on how to use the Care Innovations Guide, a telehealth remote monitoring system approved by US Food and Drug Administration (FDA), which includes an in-home tablet computer connected by Internet or 3G network to the Care Innovations Health Suite online portal (Intel-GE Care Innovations, Roseville, CA, USA). The Care Innovations Guide is connected to the glucometer via USB cables and has a touchscreen for participants to answer daily health session questions. Data are downloaded to the Health Suite for CDEs to access via the Internet. Participants received a OneTouch Ultra 2 glucometer (approved by the FDA), test supplies, and USB cables to keep (Johnson and Johnson-Lifescan Inc, Milpitas, CA, USA) at no charge. Participants returned the Care Innovations Guide when the intervention concluded.

The 84 sequential daily health sessions, designed by the research team, were delivered electronically through the Care Innovations Guide as a text document in the style of a PowerPoint slide or via short video clips. The daily health session started with an audible prompt from the Care Innovations Guide at a time convenient for the participant, then participants completed a glucose check while the glucometer was connected to the Care Innovations Guide via the USB cable. Glucose data were automatically transferred to the Care Innovations Guide at that time. Participants read brief educational content focusing on 1 or 2 key points from the American Association of Diabetes Educators AADE7 [5] self-care behaviors (healthy eating, being active, monitoring, taking medication, problem solving, reducing risks, and healthy coping) a framework for organizing education and structuring behavior change goals. An automated health session reminded participants to evaluate glucose data, using pattern management, every week and to revise or continue their personal experiment for the following week. Participants were assigned a CDE to contact by secure message or phone for diabetes-related questions, instructed to contact their primary care provider for additional health care needs, and to call 911 for emergencies.

\section{Data Review and Nurse Care Coordination}

The CDEs reviewed health session and SMBG data in the Health Suite Web portal, stratified by a stoplight system with red indicating missing data or data above or below predetermined thresholds, yellow indicating pending data, and green indicating all data within range. CDEs telephoned participants, at predetermined times, when SMBG data indicated an urgent situation, such as severe hypoglycemia ( 1 value $<50 \mathrm{mg} / \mathrm{dL}$ ) or hyperglycemia ( 1 value $>450 \mathrm{mg} / \mathrm{dL}$ ). CDEs also telephoned participants if they reported a change in their feet or a new problem with medication by answering "yes" to health session questions. The Web portal data were reviewed by CDEs during normal business hours Monday through Friday. Data entered during nonbusiness hours were reviewed the following business day. Glucose data were analyzed weekly via software specifically designed for the intervention and evaluated against ADA goals of $80-130 \mathrm{mg} / \mathrm{dL}$ before meals, $\leq 180 \mathrm{mg} / \mathrm{dL} 2$ hours postmeal, and a 30-50 point change between premeal to postmeal. After SMBG analysis, CDEs generated a virtual visit via asynchronous secure messaging through the EHR using the secure message feature. CDEs created a virtual encounter in the EHR, then "copy and pasted" a summary of SMBG pattern analysis data along with personalized feedback and individualized care coordination to reinforce action plans to create the virtual visit for both participants and providers to read (Figure 3). CDEs telephoned participants at weeks 4, 8, and 12 for a 30-minute discussion of SMBG trends, patterns, and goal achievement using motivational interviewing to identify opportunities to improve glucose values. If SMBG data did not improve after 4 weeks, CDEs discussed medication options with patients and/or primary care providers using shared decision making [29]. CDEs incorporated virtual visit data, both preprandial and postprandial glucose, to suggest medication changes, including insulin therapy. Medication changes were ordered by primary care providers via the EHR. Participants were instructed to use paired glucose testing or a monthly, 3-day 7-point glucose profile until the 6-month $\mathrm{A}_{1 \mathrm{c}}$. CDEs documented patient contact in the study database. 
Figure 3. Sample weekly paired glucose testing data analysis, by software designed for the study, and sample message text for feedback to participants through asynchronous secure messaging via the electronic health record.

\begin{tabular}{|c|c|c|c|}
\hline Date & $\begin{array}{c}\text { Premeal } \\
\text { glucose, } \\
\mathrm{mg} / \mathrm{dL} \\
(\mathrm{mmol} / \mathrm{L})\end{array}$ & $\begin{array}{c}\text { Postmeal } \\
\text { glucose, } \\
\mathrm{mg} / \mathrm{dL} \\
(\mathrm{mmol} / \mathrm{L})\end{array}$ & $\mathrm{mg} / \mathrm{dL}$ \\
\hline $6 / 2 / 2013$ & $203(11.3)$ & $218(12.1)$ & 15 \\
\hline $6 / 3 / 2013$ & $192(10.7)$ & $227(12.6)$ & 35 \\
\hline $6 / 4 / 2013$ & $256(14.2)$ & $232(12.9)$ & -24 \\
\hline $6 / 5 / 2013$ & $217(12.1)$ & $274(15.2)$ & 57 \\
\hline $6 / 6 / 2013$ & $193(10.7)$ & $277(15.4)$ & 84 \\
\hline
\end{tabular}

\section{Message Text:}

- $\mathrm{Hi}$, it looks like you have 5 sets of paired tests.

- The pre to post change is below the goal of 50 points $3 / 5$ times; 2 are above goal and average 71 .

- $0 / 5$ premeal values are within the goal of $80-130 ; 5$ are above goal and average 212 .

- $0 / 5$ postmeal values are within the goal of less than $180 ; 5$ are above goal and average 246 .

\section{Statistical Analysis}

Mixed-effects models were used to compare mean change over time in primary and secondary outcomes between groups. $\mathrm{A}_{1 \mathrm{c}}$ was measured at baseline and at approximately 3 and 6 months. Change in $\mathrm{A}_{1 \mathrm{c}}$ was evaluated by fitting different growth models. Time was represented in the models by 90 -day increments with the estimated change in $\mathrm{A}_{1 \mathrm{c}}$ equaling the amount of change of approximately 3 months. An indicator of group membership was added to the best-fitting growth model to test for differences between groups in $A_{1 c}$ at 3 and 6 months and the change in $A_{1 c}$ statistically adjusting for prestudy $A_{1 c}$. An indicator variable was added to the model that denoted whether a participant changed medication during the study and tested the effect of medication change on $\mathrm{A}_{1 \mathrm{c}}$ at 3 and 6 months, and on the change in $A_{1 c}$. Finally, a model was fit to test the effect of the number of paired glucose tests on $A_{1 c}$ at 3 and 6 months and change in $\mathrm{A}_{1 \mathrm{c}}$ over time controlling for change in medication and prestudy $A_{1 c}$. The effect of the number of paired glucose tests on $A_{1 c}$, accounting for effects due to changes in medication, was studied. Tests used a significance level of $P<.05$ or a $95 \%$ confidence interval that excluded zero. SAS version 9.4 (SAS Institute, Inc, Cary, NC, USA) was used to obtain restricted maximum-likelihood estimates using PROC MIXED.

\section{Results}

\section{Overview}

Table 1 shows baseline characteristics of participants $(\mathrm{N}=90)$. The majority were white $(64 \%, 56 / 87)$, had diabetes for a mean 8.2 (SD 5.4) years, mean age of 58 (SD 11) years, and mean $\mathrm{A}_{1 \mathrm{c}}$ of $8.3 \%$ (SD 1.1; $\left.67 \mathrm{mmol} / \mathrm{mol}\right)$. Participants were highly educated $(63 \%, 55 / 87$ college/postcollege), employed (53\%, 46/87), with previous diabetes education (86\%, 75/87), hypertension $(59 \%, 51 / 87)$, and hyperlipidemia $(69 \%, 60 / 87)$. There were no differences between groups at baseline except for self-reported hyperlipidemia $(P=.006)$ in the treatment group. All data were included in an intent-to-treat analysis. There were no serious hyper- or hypoglycemic events or hospitalizations. One participant visited the emergency department unrelated to the study and DSMB determined there were no serious adverse events related to the study. 
Table 1. Demographic and key baseline characteristics by group.

\begin{tabular}{|c|c|c|}
\hline Characteristic & $\begin{array}{l}\text { Usual care } \\
\mathrm{n}=45\end{array}$ & $\begin{array}{l}\text { Treatment } \\
\mathrm{n}=45\end{array}$ \\
\hline Female, n (\%) & $19(21)$ & $23(25)$ \\
\hline Age (years), mean (SD) & $57.5(10.6)$ & $53.9(10.4)$ \\
\hline Years with diabetes (years), ${ }^{\mathrm{a}}$ mean (SD) & $8.1(5.3)$ & $8.3(5.5)$ \\
\hline \multicolumn{3}{|l|}{ Ethnicity $^{\mathrm{a}}, \mathbf{n}(\%)$} \\
\hline Hispanic & $8(9)$ & $6(7)$ \\
\hline White & $27(31)$ & $29(33)$ \\
\hline Black/African American & $2(2)$ & $1(1)$ \\
\hline American Indian & $1(1)$ & $2(2)$ \\
\hline Asian/Pacific Islander & $4(5)$ & $3(3)$ \\
\hline Other & $1(1)$ & $2(2)$ \\
\hline Not reported & $0(0)$ & $1(1)$ \\
\hline \multicolumn{3}{|l|}{ Education $^{\mathrm{a}}, \mathrm{n}(\%)$} \\
\hline College & $18(21)$ & $17(20)$ \\
\hline High school & $10(12)$ & $16(18)$ \\
\hline Other & $3(3)$ & $3(3)$ \\
\hline Post college & $12(14)$ & $8(9)$ \\
\hline \multicolumn{3}{|l|}{ Employment status ${ }^{\mathbf{a}}, \mathbf{n}(\%)$} \\
\hline Employed & $21(24)$ & $25(29)$ \\
\hline Not employed & $6(7)$ & $6(7)$ \\
\hline Retired & $16(18)$ & $13(15)$ \\
\hline \multicolumn{3}{|l|}{ Marital status ${ }^{\mathrm{a}}, \mathbf{n}(\%)$} \\
\hline Married & $29(33)$ & $36(41)$ \\
\hline Single/divorced/widowed & $14(16)$ & $8(9)$ \\
\hline Previous diabetes education $^{\mathrm{a}}, \mathrm{n}(\%)$ & $40(46)$ & $35(40)$ \\
\hline Computer use $^{\mathrm{a}}, \mathrm{n}(\%)$ & $42(48)$ & $44(51)$ \\
\hline \multicolumn{3}{|l|}{ Type of Internet use ${ }^{a}, \mathbf{n}(\%)$} \\
\hline Email, yesterday & $34(39)$ & $41(47)$ \\
\hline News, yesterday & $24(28)$ & $34(39)$ \\
\hline Medical, yesterday & $9(10)$ & $14(16)$ \\
\hline Video, yesterday & $11(13)$ & $14(16)$ \\
\hline \multicolumn{3}{|l|}{ Treatment $^{\mathrm{a}}, \mathbf{n}(\%)$} \\
\hline Lifestyle & $2(2)$ & $3(3)$ \\
\hline Pills & $10(12)$ & $7(8)$ \\
\hline Pills and lifestyle & $27(31)$ & $30(35)$ \\
\hline Noninsulin injectable & $2(2)$ & $3(3)$ \\
\hline Noninsulin injectable and pills & $2(2)$ & $1(1)$ \\
\hline \multicolumn{3}{|l|}{ Comorbidities $^{\mathbf{a}}, \mathbf{n}(\%)$} \\
\hline Heart attack & $6(7)$ & $5(6)$ \\
\hline Coronary heart disease & $5(6)$ & $4(5)$ \\
\hline
\end{tabular}




\begin{tabular}{|c|c|c|}
\hline Characteristic & $\begin{array}{l}\text { Usual care } \\
\mathrm{n}=45\end{array}$ & $\begin{array}{l}\text { Treatment } \\
\mathrm{n}=45\end{array}$ \\
\hline Atherosclerosis & $3(3)$ & $2(2)$ \\
\hline Stroke & $3(3)$ & $0(0)$ \\
\hline Hypertension & $22(25)$ & $29(33)$ \\
\hline High cholesterol & $24(28)$ & $36(41)^{\mathrm{b}}$ \\
\hline \multicolumn{3}{|l|}{ Satisfaction with care ${ }^{a}, \mathbf{n}(\%)$} \\
\hline Strongly agree & $11(13)$ & $6(7)$ \\
\hline Somewhat agree & $14(16)$ & $13(15)$ \\
\hline Neutral & $9(10)$ & $12(14)$ \\
\hline Somewhat disagree & $8(9)$ & $6(7)$ \\
\hline Strongly disagree & $1(1)$ & $7(8)$ \\
\hline Body mass index $\left(\mathrm{kg} / \mathrm{m}^{2}\right)$, mean $(\mathrm{SD})$ & $34.1(6.6)$ & $34.1(6.8)$ \\
\hline \multicolumn{3}{|l|}{ Blood pressure (mm Hg), mean (SD) } \\
\hline Systolic & $128.8(13.9)$ & $126.9(13.2)$ \\
\hline Diastolic & $76.6(11.0)$ & $77.3(9.1)$ \\
\hline Triglycerides (mg/dL), mean (SD) & $175.5(111.3)$ & $170.5(112.3)$ \\
\hline High-density lipoprotein $(\mathrm{mg} / \mathrm{dL})$, mean (SD) & $39.8(10.6)$ & $37.9(12.2)$ \\
\hline Low-density lipoprotein (mg/dL), mean (SD) & $92.1(29.4)$ & $92.8(28.8)$ \\
\hline Cholesterol (mg/dL), mean (SD) & $164.4(35.6)$ & $161(38)$ \\
\hline \multicolumn{3}{|l|}{$\mathbf{A}_{1 \mathrm{c}}$, mean $(\mathrm{SD})$} \\
\hline$\%$ & $8.2(1.1)$ & $8.5(1.1)$ \\
\hline $\mathrm{mmol} / \mathrm{mol}$ & 7 (13) & 69 (12) \\
\hline
\end{tabular}

${ }^{\mathrm{a}}$ Missing baseline questionnaire data for 3 participants $(\mathrm{n}=87)$.

${ }^{\mathrm{b}} P=.006 ; 2$-tailed $P$ value corresponding to a test of a difference between usual care and treatment groups.

\section{Primary Outcomes}

The best-fitting model to describe $\mathrm{A}_{1 \mathrm{c}}$ over time was a quadratic growth model suggesting that the rate of change in $\mathrm{A}_{1 \mathrm{c}}$ was not constant over time. The quadratic model included 3 coefficients. The first two, the intercept and the linear change rate, described $\mathrm{A}_{1 \mathrm{c}}$ level and change in $\mathrm{A}_{1 \mathrm{c}}$ at specific time points. We evaluated these 2 coefficients at baseline and at 3- and 6-months postbaseline. Time was coded to reflect change at approximately 3-month intervals; thus, the linear change rate was the expected rate of change using a 90-day interval. The third coefficient, the quadratic effect, was the acceleration rate that allowed for a nonconstant rate of change over time. Of the 3 coefficients, only the intercept varied across individuals suggesting individual differences in $\mathrm{A}_{1 \mathrm{c}}$ levels over time, but no significant individual differences in the change rate. After fitting a growth model to data, individual scores may correlate between measurements. Model fit for $\mathrm{A}_{1 \mathrm{c}}$ scores was improved by allowing the residuals between measurements to correlate within persons.

Using a quadratic growth model to describe $\mathrm{A}_{1 \mathrm{c}}$ over time, we tested group differences in $\mathrm{A}_{1 \mathrm{c}}$ levels and the linear rates of change at baseline and at 3 and 6 months controlling for prestudy $\mathrm{A}_{1 \mathrm{c}}$. Comparisons between usual care group and treatment group suggested no difference in mean $\mathrm{A}_{1 \mathrm{c}}$ or in the linear change rate at baseline. An estimated group mean $A_{1 c}$ difference of 0.11 $\left(t_{159}=0.63, P=.53\right)$ at 3 months and $-0.11\left(t_{159}=-0.59, P=.55\right)$ at 6 months showed no significant differences between groups. At 3 months, the usual care group decreased $A_{1 c}$ at a mean rate of -0.35 units $\left(t_{159}=-4.37, P<.001\right)$. Between groups, the difference in the change rate of $-0.21\left(t_{159}=-1.87, P=.06\right)$ was not significant, suggesting no difference in the change rate at 3 months. At 6 months, the change rate in $A_{1 c}$ for the usual care group of $-0.07 \quad\left(t_{159}=-1.41, P=.16\right)$ was not statistically significant, indicating no further improvement in $A_{1 c}$ at 6 months. However, the groups differed significantly in the change rate at 6 months, with the treatment group decreasing 0.23 units faster than the usual care group $\left(t_{159}=-2.87, P=.005\right)$ (Table 2$)$. Figure 4 shows $A_{1 c}$ trajectories for groups over 6 months. Finally, the estimated acceleration rate for the usual care group was $0.14\left(t_{159}=4.07, P<.001\right)$, suggesting that the change rate increased with time. The estimated acceleration rate for the treatment group was $0.14+(-0.013)=0.13$, although the difference in this coefficient between groups was not significant $\left(t_{159}=-0.26, P=.80\right)$ suggesting no difference in this aspect of change in $\mathrm{A}_{1 \mathrm{c}}$ over time. 
Table 2. Estimated mean $A_{1 c}$ level and instantaneous linear change in $A_{1 c}$ at baseline and 3 and 6 months with group differences and prestudy $A_{1 c}$ level as a covariate. ${ }^{\mathrm{a}}$

\begin{tabular}{|c|c|c|c|c|c|c|}
\hline Factor & $\mathrm{n}$ & Usual care group & Treatment group & Group difference & $t$-ratio $159{ }^{\mathrm{b}}$ & $P$ \\
\hline \multicolumn{7}{|l|}{ Mean A 1c level, \% (mmol/mol) } \\
\hline Baseline & 90 & $8.16(66)$ & $8.46(69)$ & 0.30 & 1.57 & .12 \\
\hline 3 months & 83 & $7.68(60)$ & $7.81(62)$ & 0.11 & 0.63 & .53 \\
\hline 6 months & 80 & $7.46(58)$ & $7.35(57)$ & -0.11 & -0.59 & .55 \\
\hline Prestudy $A_{1 c}$ effect $^{c}$ & & 0.52 & - & - & 5.23 & $<.001$ \\
\hline \multicolumn{7}{|c|}{ Instantaneous linear change in $A c^{d}$} \\
\hline Baseline & 90 & -0.62 & -0.80 & -0.18 & -0.94 & .35 \\
\hline 3 months & 83 & -0.35 & -0.56 & -0.21 & -1.87 & .06 \\
\hline 6 months & 80 & -0.07 & -0.31 & -0.23 & -2.87 & .005 \\
\hline $\begin{array}{l}\text { Estimated change from baseline to } \\
6 \text { months }\end{array}$ & & -0.70 & -1.11 & -0.41 & & \\
\hline Acceleration rate $\mathrm{e}^{\mathrm{e}}$ & & 0.14 & 0.12 & -0.01 & -0.26 & .80 \\
\hline
\end{tabular}

${ }^{\text {a }}$ Tabled values are maximum-likelihood estimates.

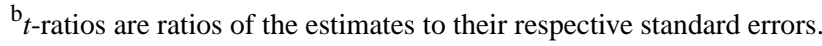

${ }^{\mathrm{c}}$ The prestudy $\mathrm{A}_{1 \mathrm{c}}$ effect, a regression coefficient, is the change in $\mathrm{A}_{1 \mathrm{c}}$ when measured during the study for a unit increase in prestudy $\mathrm{A}_{1 \mathrm{c}}$ level.

${ }^{d}$ Instantaneous linear change in $A_{1 c}$ reflects the point change in $A_{1 c}$ for a 90-day increment.

${ }^{\mathrm{e}}$ Acceleration rate is the rate of acceleration of the quadratic growth model. 
Figure 4. Estimated A1C trajectories for the usual care and treatment groups from baseline to 6 months.

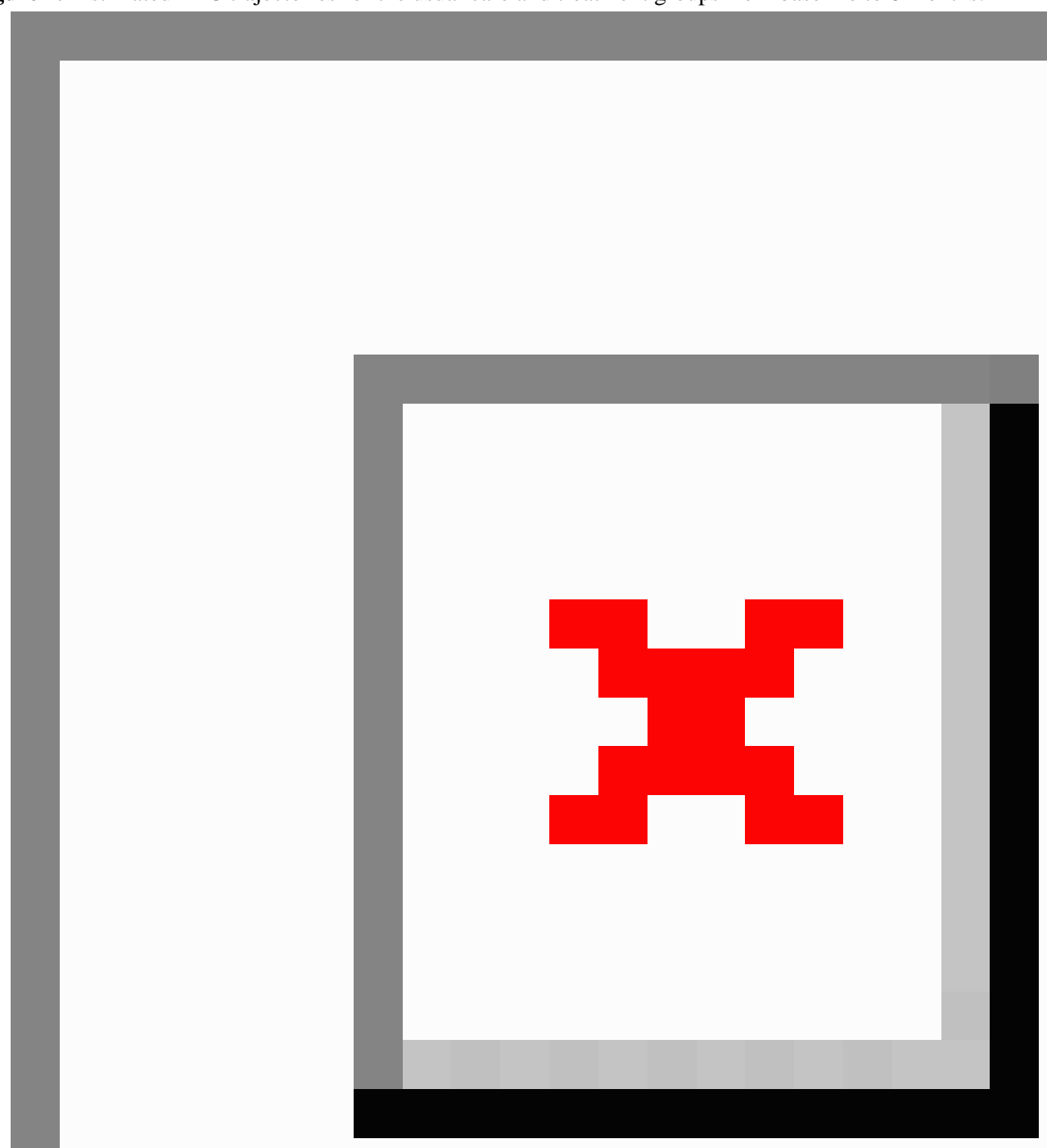

One usual care participant and 27 participants in the treatment group self-reported medication change, including 4 starting insulin. A change in medication was related to lower $A_{1 c}$ at 3 months $\left(t_{157}=-3.42, P<.001\right.$ and 6 months $\left(t_{157}=-3.37, P<.001\right)$ controlling for treatment effect and prestudy $\mathrm{A}_{1 \mathrm{c}}$. The effect of a medication change was not significant on the change rate in $A_{1 c}$ at 3 or 6 months (see Table 3). Three usual care group participants engaged with CDEs via telephone during the study. Although only 1 participant changed medication, they all decreased their $\mathrm{A}_{1 \mathrm{c}}$ levels.
The paired glucose testing goal was 84 pairs over 12 weeks with actual values ranging from zero to 73 pairs, mean 10.2 (SD 14.4) pairs, and median 21 (IQR 15) pairs. The effect of the number of paired glucose tests was not statistically significant on either the level $\left(t_{156}=-0.99, P=.33\right)$ or change rate in $\mathrm{A}_{1 \mathrm{c}}$ at 3 months $\left(t_{156}=-1.82, P=.07\right)$ and the level $\left(t_{156}=-1.86, P=.06\right)$ or change rate in $\mathrm{A}_{1 \mathrm{c}}$ at 6 months $\left(t_{156}=-1.82, P=.07\right.$ ) (see Table 3). 
Table 3. Estimated effects of change in medication and number of paired glucose tests on $A_{1 c}$ level and instantaneous linear change in $A_{1 c}$ at baseline and at 3 and 6 months.

\begin{tabular}{|c|c|c|c|c|c|c|}
\hline \multirow[t]{2}{*}{ Predictor } & \multicolumn{3}{|c|}{ Estimated effect on $\mathrm{A}_{1 \mathrm{c}}$ level $^{\mathrm{a}}$} & \multicolumn{3}{|c|}{ Estimated effect on the instantaneous linear change rate in $\mathrm{A}_{1}$} \\
\hline & $M_{L} E^{b}$ & $t$-ratio $(d f)^{\mathrm{c}}$ & $P$ & $M_{L E}{ }^{b}$ & $t$-ratio $(d f)^{\mathrm{c}}$ & $P$ \\
\hline \multicolumn{7}{|c|}{ Medication change } \\
\hline 3 months & -1.05 & $-3.42(157)$ & $<.001$ & 0.35 & $1.81(157)$ & .07 \\
\hline 6 months & -0.71 & $-3.37(157)$ & $<.001$ & 0.35 & $1.81(157)$ & .07 \\
\hline \multicolumn{7}{|c|}{ Number of paired tests } \\
\hline 3 months & -0.007 & $-0.99(156)$ & .33 & -0.008 & $-1.82(156)$ & .07 \\
\hline 6 months & -0.015 & $-1.86(156)$ & .06 & -0.008 & $-1.82(156)$ & .07 \\
\hline
\end{tabular}

${ }^{\text {a }}$ Models were estimated in a hierarchical fashion.

${ }^{\mathrm{b}}$ MLE: maximum-likelihood estimate.

${ }^{c} t$-ratios are ratios of the estimates to their respective standard errors.

\section{Secondary Outcomes}

Table 4 shows secondary outcomes by group over 3 months. Both groups showed improvement on average for general diet, specific diet, carbohydrate spacing, and foot care self-management behaviors measured by the SDSCA. The treatment group showed greater improvement in the self-management behaviors of carbohydrate spacing, monitoring glucose, and foot care. Neither group showed improvement in DKT, DES, or SDSCA subscales of exercise, smoking, and medication. 
Table 4. Patient-reported secondary outcomes by group.

\begin{tabular}{|c|c|c|c|c|c|c|}
\hline \multirow[t]{2}{*}{ Secondary outcome ${ }^{\mathrm{a}}$} & \multicolumn{2}{|c|}{ Usual care } & \multicolumn{2}{|c|}{ Treatment } & \multirow[t]{2}{*}{$t$-ratio $(d f)$} & \multirow[t]{2}{*}{$P$} \\
\hline & $\mathrm{n}$ & Mean $(95 \% \mathrm{CI})$ & $\mathrm{n}$ & Mean $(95 \% \mathrm{CI})$ & & \\
\hline \multicolumn{7}{|l|}{ DES } \\
\hline Baseline & 42 & $3.5(3.3,3.8)$ & 45 & $3.8(3.2,4.4)$ & $1.32(85)$ & .19 \\
\hline 3 months & 41 & $3.8(3.2,3.3)$ & 40 & $4.1(2.8,5.3)^{\mathrm{b}}$ & $0.39(78)$ & .70 \\
\hline \multicolumn{7}{|l|}{ DKT } \\
\hline Baseline & 42 & $12.0(11.3,12.6)$ & 45 & $12.4(10.9,13.9)$ & $0.98(85)$ & .33 \\
\hline 3 months & 41 & $11.4(10.1,12.6)$ & 40 & $12.1(9.1,14.0)^{\mathrm{b}}$ & $0.61(78)$ & .55 \\
\hline \multicolumn{7}{|l|}{ SDSCA } \\
\hline \multicolumn{7}{|l|}{ General diet } \\
\hline Baseline & 42 & $3.7(3.2,4.3)$ & 45 & $3.7(2.4,5.0)$ & $-0.07(85)$ & .95 \\
\hline 3 months & 41 & $4.9(3.7,6.1)$ & 40 & $4.7(2.0,7.0)^{\mathrm{b}}$ & $-0.20(78)$ & .84 \\
\hline \multicolumn{7}{|l|}{ Specific diet } \\
\hline Baseline & 42 & $2.9(2.4,3.4)$ & 45 & $3.5(2.3,4.7)$ & $1.69(85)$ & .09 \\
\hline 3 months & 41 & $4.2(3.0,5.3)$ & 40 & $4.6(1.7,7.0)^{\mathrm{b}}$ & $-0.41(78)$ & .68 \\
\hline \multicolumn{7}{|c|}{ Carbohydrate spacing } \\
\hline Baseline & 42 & $3.0(2.3,3.8)$ & 45 & $2.7(1.0,4.6)$ & $-0.46(85)$ & .65 \\
\hline 3 months & 41 & $3.9(2.4,5.4)$ & 40 & $4.7(3.4,7.0)^{\mathrm{b}}$ & $2.08(78)$ & .04 \\
\hline \multicolumn{7}{|l|}{ Exercise } \\
\hline Baseline & 42 & $2.4(1.7,3.1)$ & 45 & $2.7(1.1,4.3)$ & $0.56(85)$ & .58 \\
\hline 3 months & 41 & $2.6(1.3,3.9)$ & 40 & $3.7(0.60,6.8)$ & $1.82(78)$ & .07 \\
\hline \multicolumn{7}{|l|}{ Medication } \\
\hline Baseline & 42 & $6.5(6.0,7.0)$ & 45 & $6.2(4.9,7.0)^{\mathrm{b}}$ & $-0.93(85)$ & .35 \\
\hline 3 months & 41 & $6.4(5.4,7.3)$ & 40 & $6.3(5.2,7.0)^{\mathrm{b}}$ & $0.95(78)$ & .34 \\
\hline \multicolumn{7}{|l|}{ Monitoring glucose } \\
\hline Baseline & 42 & $3.6(2.8,4.4)$ & 45 & $3.0(1.1,4.8)$ & $-1.17(85)$ & .25 \\
\hline 3 months & 41 & $3.7(2.1,5.3)$ & 40 & $5.1(2.6,7.0)^{\mathrm{b}}$ & $3.31(78)$ & .001 \\
\hline \multicolumn{7}{|l|}{ Foot care } \\
\hline Baseline & 42 & $2.5(1.8,3.2)$ & 45 & $2.5(0.9,4.2)$ & $0.04(85)$ & .97 \\
\hline 3 months & 41 & $3.8(2.5,5.2)$ & 40 & $5.0(1.7,7.0)^{\mathrm{b}}$ & $2.42(78)$ & .02 \\
\hline
\end{tabular}

${ }^{a}$ DES: Diabetes Empowerment Scale; DKT: Diabetes Knowledge Test; SDSCA: Summary of Diabetes Self-Care Activities.

${ }^{\mathrm{b}}$ Confidence intervals assume symmetry about the mean, reported with the maximum scale score as the upper bound contained within the interval estimate; DES max score=5.0; DKT $\max$ score=14.0; SDSCA $\max$ score=7.0.

\section{Discussion}

\section{Principal Findings}

To our knowledge, this is the first telehealth remote monitoring study for type 2 diabetes, within a diabetes management program, that incorporated all essential elements of structured monitoring, including (1) identifying frequency of glucose testing, (2) participant use and response to data, (3) health care provider data interpretation, and (4) therapy modifications $[12,13]$ with paired glucose testing [22]. Structured monitoring created actionable patient-generated data in the context of a complete feedback loop facilitating change in both self-management behavior and treatment. In this study, both groups had improved $\mathrm{A}_{1 \mathrm{c}}$ levels at 3 months without a significant difference between groups in the rate of change $(P=.06)$. However, at 6 months, the treatment group continued to have a statistically significant decrease in $\mathrm{A}_{1 \mathrm{c}}$ levels (demonstrating sustained benefit from the intervention), whereas the usual care group participants were no longer improving $(P=.005)$. Both groups had lower $\mathrm{A}_{1 \mathrm{c}}$ levels with an estimated average decrease of 0.70 percentage points in the usual care group and 1.11 
percentage points in the treatment group, with a significant group difference of 0.41 percentage points at 6 months. Although baseline $\mathrm{A}_{1 \mathrm{c}}$ levels were higher in the treatment group, it was not significantly different from the usual care group. These outcomes are similar to a recent systematic review and meta-analysis that demonstrated a statistically significant and clinically relevant mean difference in $\mathrm{A}_{1 \mathrm{c}}$ of -0.44 percentage points $(-4.8 \mathrm{mmol} / \mathrm{mol})$ between treatment and usual care when telehealth was added to usual care in diabetes management [30]. Previously, a difference of -0.50 percentage points in $\mathrm{A}_{1 \mathrm{c}}$ levels between treatment and usual care groups has been reported as clinically meaningful in the literature [14]. Implementation of all complete feedback loop elements (telehealth remote monitoring, structured SMBG, nurse care coordination, and treatment change) is necessary to improve outcomes and future clinical translational research needs to be conducted in the context of the complete feedback loop [20].

Reducing clinical inertia in management of type 2 diabetes was a goal of this intervention [3]. In this study, treatment participants had more self-reported medication changes compared to usual care participants and this was significantly associated with $\mathrm{A}_{1 \mathrm{c}}$ level at both $3(P<.001)$ and 6 months $(P<.001)$. The weekly asynchronous virtual visits provided analyzed glucose data to reinforce ADA goals and facilitate pattern management. The paired glucose testing analysis reduced clinical inertia for both patients and providers. Evaluating multiple weeks of SMBG data, often continuously above goal, compared to the usual practice of assessing a single $A_{1 c}$ result at 3-month intervals, encouraged medication change. This study is similar to others that incorporated nurse care coordination $[25,31,32]$ to suggest medication changes to primary care providers, but different from those that used nurse practitioners $[33,34]$ who were able to adjust medication independently. Although CDEs suggested medication changes, the primary care providers did not always follow the recommendations or ordered a different medication class. Allowing CDEs to adjust and order medications independently might improve outcomes. Although primary care providers had access to paired glucose testing data analysis, several chose to wait for $\mathrm{A}_{1 \mathrm{c}}$ results before initiating medication change. Targeted primary care provider education before the study may have improved outcomes and increased comfort level with adjusting medications using SMBG data [35].

In the telehealth literature, some studies report an association between the frequency of SMBG and the impact on $\mathrm{A}_{1 \mathrm{c}}$ change $[33,36]$, whereas others report no impact [34]. The STeP study showed structured SMBG data resulted in more frequent and effective treatment changes by primary care providers [6]. The St Carlos [7], ROSSO [37], and PRISMA [17] studies also showed improvement in $A_{1 c}$ when structured SMBG data were used to adjust treatment. In this study, more sets of paired glucose testing were not associated with a faster rate of decline in $\mathrm{A}_{1 \mathrm{c}}$ levels $(P=.06)$. However, the frequency of paired glucose testing varied. Identifying opportunities to encourage consistent paired glucose testing may improve outcomes. Research to examine the minimum number of paired glucose tests required to improve outcomes is important. The study was not powered to conduct subanalyses of individuals with consistent weekly paired glucose testing. Newer glucose monitoring technologies, including continuous glucose sensors that collect and store glucose data with minimal fingerstick requirements, may improve primary care provider and patient access to glucose data and reduce clinical inertia. Finally, long-term use of paired glucose testing over 12 months needs to be evaluated. Although $A_{1 c}$ data were collected at 6 months, the active intervention ended at 3 months. It is possible that continuing the telehealth remote monitoring would further improve outcomes. A comparative effectiveness study varying the frequency of paired glucose testing and type of remote monitoring feedback is necessary to identify best practices to lower $\mathrm{A}_{1 \mathrm{c}}$ levels [38].

This telehealth study incorporated asynchronous virtual encounters via the EHR to provide feedback on the weekly analysis of paired glucose testing data. This study was similar to others that focused on the use of EHRs for feedback $[33,39,40]$, allowing participants to engage in self-management at a convenient time. This study was also similar to others that analyzed data using treatment algorithms [32], but offered a unique approach by using paired glucose testing data to educate the participant on glucose pattern management and empower participants in self-management.

The treatment group improved in 3 self-management behaviors. Daily education on AADE7 self-care behaviors required the participant to respond through the Care Innovations Guide [5]. The treatment group showed greater improvement in SDSCA self-management subscores of foot care, carbohydrate spacing, and monitoring glucose, all content areas presented in the Care Innovations Guide. The asynchronous virtual visits concentrated on the impact of paired glucose testing and helped participants evaluate carbohydrate quantity in food choices while identifying effect on glucose. This telehealth remote monitoring study is unique in that the participants were taught to analyze paired glucose testing data in the same manner as CDEs, looking for trends and patterns, and adjusting behavior accordingly. Data from a recent systematic review showed that only $31.1 \%$ of mobile apps create an opportunity for people with diabetes to share glucose data with providers and even fewer (17.8\%) offer an opportunity to analyze data and graphically display results to help the individual learn from their data, whereas only $8.8 \%$ of applications supported patients in developing personalized action plans [38]. This study improved on limitations identified in this systematic review by sharing glucose data with the health care team, providing both automated and tailored feedback along with problem solving and goal setting support. Although foot care was not directly an intervention component, foot care was incorporated into the 84 virtual health sessions participants completed through the Care Innovations Guide. Participants improved scores in foot care due to the daily educational content provided through the Care Innovations Guide, which indicates virtual education is a successful option to improve self-management behaviors.

\section{Limitations}

Due to challenges with recruitment and saturation of the participant pool, the sample size was small. Results may be different for larger studies powered to detect a smaller change 
in $A_{1 c}$ levels. The study took place over 6 months, thus long-term outcomes and sustainability over time is unknown. Although there are baseline data from the SDSCA subscale on glucose monitoring, we do not know if the usual care group engaged in paired glucose testing or another profile. However, most participants self-reported not checking glucose on a regular schedule and randomization would account for this issue. A Hawthorne effect is always possible when enrolling individuals motivated to change their self-management behaviors. A delayed entry or a crossover study would address the problem of usual care participants knowing group assignment. The population for the study was an existing diabetes management program, a higher level of usual care than described in most telehealth remote monitoring studies, so between-group differences may be smaller than if compared to typical usual care. Data were not collected on specific dietary or physical activity changes participants made. An online food diary and accelerometer to automatically capture physical activity would create a richer dataset to analyze. Although a treatment fidelity plan was in place, the same CDEs were responsible for treatment and usual care groups, possibly contaminating the usual care group. This intervention did not use mobile technology and was unable to provide real-time feedback, which may have limited outcomes [32].

This study enrolled insured, English-speaking participants in a diabetes management program in a health system. There may be membership bias because the study was conducted in English, yet people affected by diabetes represent multiple ethnic groups, many of whom are underinsured or uninsured. A majority of the participants were white, highly educated, with a strong history of computer use. The results of this study can only be generalized to a similar population. This study should be repeated in populations of lower socioeconomic status without access to sophisticated diabetes management programs. Varying the length of telehealth remote monitoring interventions, including duration and intensity, may help define specific requirements to improve outcomes [41]. There are significant costs associated with SMBG that impact patients and payers and a cost-effectiveness analysis would have provided important information. This intervention required 2 test strips per day whereas Medicare allows for 1 strip per day. Nurse care coordination is expensive and other technology-enabled models of care that facilitate the complete feedback loop and increase patient engagement at a lower cost are needed. Incorporating social media for patient support may reinforce problem solving and behavior change and be less costly. Weitzman and colleagues [42] identified that $31.7 \%$ of study participants posted their $A_{1 c}$ values on their profile page during a study in the diabetes online community Tudiabetes.org indicating an interest in participating in online peer support for glucose management.

\section{Conclusions}

This eHealth clinical trial implemented essential elements of structured monitoring in tandem with telehealth remote monitoring and asynchronous virtual visits through a health system EHR. The complete feedback loop was utilized to educate participants, obtain and analyze actionable SMBG data, provide feedback, and collaborate as a team in the decision-making process. Participants used paired glucose testing data to change behavior, self-reporting an increase in both carbohydrate spacing and glucose monitoring. CDEs, experienced in pattern management and medication adjustment, suggested treatment changes in a reasonable time frame (typically 4 weeks), breaking a link in the cycle of clinical inertia, showing a change in medication was associated with a lower $A_{1 c}$ level [3]. At present, this level of nurse care coordination has limited reimbursement. Further research is needed to support eHealth models of care that incorporate remote nurse care coordination by CDEs [43]. Implementing a complete feedback loop in the primary care setting, supported by telehealth remote monitoring and paired glucose testing, improves $A_{1 c}$ and self-management behaviors in adults with type 2 diabetes.

\section{Acknowledgments}

This research project has research support from the Investigator Initiated Studies program of LifeScan Corporation, Intel-GE Care Innovations, Sutter Institute for Medical Research, The Betty Irene Moore School of Nursing, The Jonas Center for Nursing Excellence, and the University of California Davis, National Center for Advancing Translational Sciences, National Institutes of Health, through grant number UL1 TR 000002. The funders of this study did not play a role in the design and conduct of the study; collection, management, analysis, and interpretation of the data; or in the preparation of the manuscript. Intel-GE Care Innovations did not have veto power over or have say about changing any manuscript text other than the description of the hardware and software they provided. The authors thank Van Luong, Carla Johnson, Joan Olveda, Tom Leonard, and Kimberly Buss, Sutter Health Disease Management Program, for managing the intervention and providing medical and nursing guidance; Brooke Adamska, Sutter Health Disease Management Program, the study coordinator; Dorothy Wullenwaber, Sutter Institute for Medical Research for recruitment; Andrea Hankins, Sutter Institute for Medical Research for database development and data analysis support and Carol Parise, Sutter Institute for Medical Research, for statistical guidance.

\section{Authors' Contributions}

DAG was Principal Investigator for the study. DAG, HMY, TSN, SAB, and CCQ were responsible for the conception, design, interpretation of data, revising manuscript for intellectual content, and final approval of published version. DAG was responsible for acquisition of data; DAG and SAB performed data analysis; DAG, SAB, HMY, and CCQ drafted the paper. DAG is the guarantor of this work and, as such, had full access to all the data in the study and takes responsibility for the integrity of the data and the accuracy of the data analysis. 


\section{Conflicts of Interest}

DAG received research support from the Investigator Initiated Studies program of LifeScan Corporation and Intel-GE Care Innovations. No other conflicts are declared.

\section{Multimedia Appendix 1 \\ CONSORT-EHEALTH checklist V1.6.2 [44].}

[PDF File (Adobe PDF File), 145KB-Multimedia Appendix 1]

\section{Multimedia Appendix 2}

Greenwood clinical inertia RCT PowerPoint presentation.

[PPTX File, 1MB-Multimedia Appendix 2]

\section{References}

1. Centers for Disease Control and Prevention. National Diabetes Statistics Report: Estimates of Diabetes and Its Burden in the United States, 2014. Atlanta, GA: US Department of Health and Human Services; 2014. URL: http://www.cdc.gov/ diabetes/data/statistics/2014StatisticsReport.html [accessed 2015-07-03] [WebCite Cache ID 6a9WnQFBA]

2. American Diabetes Association. Standards of medical care in diabetes-2015 abridged for primary care providers. Clin Diabetes 2015 Apr;33(2):97-111. [doi: 10.2337/diaclin.33.2.97] [Medline: 25897193]

3. Khunti K, Wolden ML, Thorsted BL, Andersen M, Davies MJ. Clinical inertia in people with type 2 diabetes: a retrospective cohort study of more than 80,000 people. Diabetes Care 2013 Nov;36(11):3411-3417 [FREE Full text] [doi: 10.2337/dc13-0331] [Medline: 23877982]

4. Ziemer DC, Miller CD, Rhee MK, Doyle JP, Watkins C, Cook CB, et al. Clinical inertia contributes to poor diabetes control in a primary care setting. Diabetes Educ 2005;31(4):564-571. [doi: 10.1177/0145721705279050] [Medline: 16100332]

5. Burke SD, Sherr D, Lipman RD. Partnering with diabetes educators to improve patient outcomes. Diabetes Metab Syndr Obes 2014;7:45-53 [FREE Full text] [doi: 10.2147/DMSO.S40036] [Medline: 24550679]

6. Polonsky WH, Fisher L, Schikman CH, Hinnen DA, Parkin CG, Jelsovsky Z, et al. A structured self-monitoring of blood glucose approach in type 2 diabetes encourages more frequent, intensive, and effective physician interventions: results from the STeP study. Diabetes Technol Ther 2011 Aug;13(8):797-802. [doi: 10.1089/dia.2011.0073] [Medline: 21568751]

7. Durán A, Martín P, Runkle I, Pérez N, Abad R, Fernández M, et al. Benefits of self-monitoring blood glucose in the management of new-onset Type 2 diabetes mellitus: the St Carlos Study, a prospective randomized clinic-based interventional study with parallel groups. J Diabetes 2010 Sep;2(3):203-211. [doi: 10.1111/j.1753-0407.2010.00081.x] [Medline: 20923485]

8. Bonomo K, De SA, Fiora E, Mularoni E, Massucco P, Poy P, et al. Evaluation of a simple policy for pre- and post-prandial blood glucose self-monitoring in people with type 2 diabetes not on insulin. Diabetes Res Clin Pract 2010 Feb;87(2):246-251. [doi: 10.1016/j.diabres.2009.10.021] [Medline: 19954855]

9. Funnell MM, Brown TL, Childs BP, Haas LB, Hosey GM, Jensen B, et al. National standards for diabetes self-management education. Diabetes Care 2012 Jan;35 Suppl 1:S101-S108 [FREE Full text] [doi: 10.2337/dc12-s101] [Medline: 22187467]

10. International Diabetes Federation. 2009. Self-monitoring of blood glucose in non-insulin-treated type 2 diabetes URL: http://www.idf.org/guidelines/self-monitoring [accessed 2015-07-03] [WebCite Cache ID 6Zklf8xjx]

11. Stetson B, Schlundt D, Peyrot M, Ciechanowski P, Austin MM, Young-Hyman D, et al. Monitoring in diabetes self-management: issues and recommendations for improvement. Popul Health Manag 2011 Aug;14(4):189-197. [doi: 10.1089/pop.2010.0030] [Medline: 21323462]

12. Parkin CG, Hinnen D, Campbell RK, Geil P, Tetrick DL, Polonsky WH. Effective use of paired testing in type 2 diabetes: practical applications in clinical practice. Diabetes Educ 2009;35(6):915-927. [doi: 10.1177/0145721709347601] [Medline: 19789359]

13. Polonsky WH, Fisher L, Schikman CH, Hinnen DA, Parkin CG, Jelsovsky Z, et al. Structured self-monitoring of blood glucose significantly reduces A1C levels in poorly controlled, noninsulin-treated type 2 diabetes: results from the Structured Testing Program study. Diabetes Care 2011 Feb;34(2):262-267 [FREE Full text] [doi: 10.2337/dc10-1732] [Medline: 21270183]

14. Klonoff DC, Blonde L, Cembrowski G, Chacra AR, Charpentier G, Colagiuri S, Coalition for Clinical Research-Self-Monitoring of Blood Glucose Scientific Board. Consensus report: the current role of self-monitoring of blood glucose in non-insulin-treated type 2 diabetes. J Diabetes Sci Technol 2011 Nov;5(6):1529-1548 [FREE Full text] [Medline: 22226276]

15. Malanda UL, Welschen LM, Riphagen I, Dekker JM, Nijpels G, Bot SD. Self-monitoring of blood glucose in patients with type 2 diabetes mellitus who are not using insulin. Cochrane Database Syst Rev 2012;1:CD005060. [doi:

10.1002/14651858.CD005060.pub3] [Medline: 22258959] 
16. Franciosi M, Lucisano G, Pellegrini F, Cantarello A, Consoli A, Cucco L, et al. ROSES: role of self-monitoring of blood glucose and intensive education in patients with Type 2 diabetes not receiving insulin. A pilot randomized clinical trial. Diabet Med 2011 Jul;28(7):789-796. [doi: 10.1111/j.1464-5491.2011.03268.x] [Medline: 21342243]

17. Bosi E, Scavini M, Ceriello A, Cucinotta D, Tiengo A, Marino R, et al. Intensive structured self-monitoring of blood glucose and glycemic control in noninsulin-treated type 2 diabetes: the PRISMA randomized trial. Diabetes Care 2013 Oct;36(10):2887-2894 [FREE Full text] [doi: 10.2337/dc13-0092] [Medline: 23735724]

18. Schnell O, Alawi H, Battelino T, Ceriello A, Diem P, Felton A, et al. Addressing schemes of self-monitoring of blood glucose in type 2 diabetes: a European perspective and expert recommendation. Diabetes Technol Ther 2011 Sep;13(9):959-965. [doi: 10.1089/dia.2011.0028] [Medline: 21714682]

19. Jimison H, Gorman P, Woods S, Nygren P, Walker M, Norris S, et al. Barriers and drivers of health information technology use for the elderly, chronically ill, and underserved. Evid Rep Technol Assess (Full Rep) 2008 Nov(175):1-1422. [Medline: $\underline{19408968]}$

20. Ceriello A, Barkai L, Christiansen JS, Czupryniak L, Gomis R, Harno K, et al. Diabetes as a case study of chronic disease management with a personalized approach: the role of a structured feedback loop. Diabetes Res Clin Pract 2012 Oct;98(1):5-10. [doi: 10.1016/j.diabres.2012.07.005] [Medline: 22917639]

21. Boren SA, Puchbauer AM, Williams F. Computerized prompting and feedback of diabetes care: a review of the literature. J Diabetes Sci Technol 2009 Jul;3(4):944-950 [FREE Full text] [Medline: 20144344]

22. Greenwood DA, Young HM, Quinn CC. Telehealth remote monitoring systematic review: structured self-monitoring of blood glucose and impact on A1C. J Diabetes Sci Technol 2014 Feb 21;8(2):378-389. [doi: 10.1177/1932296813519311] [Medline: 24876591]

23. Schnell O, Alawi H, Battelino T, Ceriello A, Diem P, Felton AM, et al. Self-monitoring of blood glucose in type 2 diabetes: recent studies. J Diabetes Sci Technol 2013;7(2):478-488 [FREE Full text] [Medline: 23567007]

24. Darkins A, Ryan P, Kobb R, Foster L, Edmonson E, Wakefield B, et al. Care Coordination/Home Telehealth: the systematic implementation of health informatics, home telehealth, and disease management to support the care of veteran patients with chronic conditions. Telemed J E Health 2008 Dec;14(10):1118-1126. [doi: 10.1089/tmj.2008.0021] [Medline: 19119835]

25. Shea S, Weinstock RS, Starren J, Teresi J, Palmas W, Field L, et al. A randomized trial comparing telemedicine case management with usual care in older, ethnically diverse, medically underserved patients with diabetes mellitus. J Am Med Inform Assoc 2006;13(1):40-51 [FREE Full text] [doi: 10.1197/jamia.M1917] [Medline: 16221935]

26. Fitzgerald JT, Funnell MM, Hess GE, Barr PA, Anderson RM, Hiss RG, et al. The reliability and validity of a brief diabetes knowledge test. Diabetes Care 1998 May;21(5):706-710. [Medline: 9589228]

27. Toobert DJ, Hampson SE, Glasgow RE. The summary of diabetes self-care activities measure: results from 7 studies and a revised scale. Diabetes Care 2000 Jul;23(7):943-950 [FREE Full text] [Medline: 10895844]

28. Anderson RM, Fitzgerald JT, Gruppen LD, Funnell MM, Oh MS. The Diabetes Empowerment Scale-Short Form (DES-SF). Diabetes Care 2003 May;26(5):1641-1642. [Medline: 12716841]

29. Inzucchi SE, Bergenstal RM, Buse JB, Diamant M, Ferrannini E, Nauck M, et al. Management of hyperglycemia in type 2 diabetes, 2015: a patient-centered approach: update to a position statement of the American Diabetes Association and the European Association for the Study of Diabetes. Diabetes Care 2015 Jan;38(1):140-149. [doi: 10.2337/dc14-2441] [Medline: $\underline{25538310]}$

30. Marcolino MS, Maia JX, Alkmim Maria Beatriz Moreira, Boersma E, Ribeiro AL. Telemedicine application in the care of diabetes patients: systematic review and meta-analysis. PLoS One 2013 Nov;8(11):e79246 [FREE Full text] [doi:

10.1371/journal.pone.0079246] [Medline: 24250826]

31. Wakefield BJ, Holman JE, Ray A, Scherubel M, Adams MR, Hillis SL, et al. Effectiveness of home telehealth in comorbid diabetes and hypertension: a randomized, controlled trial. Telemed J E Health 2011 May;17(4):254-261. [doi: 10.1089/tmj.2010.0176] [Medline: 21476945]

32. Quinn CC, Shardell MD, Terrin ML, Barr EA, Ballew SH, Gruber-Baldini AL. Cluster-randomized trial of a mobile phone personalized behavioral intervention for blood glucose control. Diabetes Care 2011 Sep;34(9):1934-1942 [FREE Full text] [doi: 10.2337/dc11-0366] [Medline: 21788632]

33. Tang PC, Overhage JM, Chan AS, Brown NL, Aghighi B, Entwistle MP, et al. Online disease management of diabetes: engaging and motivating patients online with enhanced resources-diabetes (EMPOWER-D), a randomized controlled trial. J Am Med Inform Assoc 2013 May 1;20(3):526-534 [FREE Full text] [doi: 10.1136/amiajnl-2012-001263] [Medline: 23171659]

34. Stone RA, Rao RH, Sevick MA, Cheng C, Hough LJ, Macpherson DS, et al. Active care management supported by home telemonitoring in veterans with type 2 diabetes: the DiaTel randomized controlled trial. Diabetes Care 2010 Mar;33(3):478-484 [FREE Full text] [doi: 10.2337/dc09-1012] [Medline: 20009091]

35. Polonsky WH, Jelsovsky Z, Panzera S, Parkin CG, Wagner RS. Primary care physicians identify and act upon glycemic abnormalities found in structured, episodic blood glucose monitoring data from non-insulin-treated type 2 diabetes. Diabetes Technol Ther 2009 May;11(5):283-291. [doi: 10.1089/dia.2008.0087] [Medline: 19425876]

36. McMahon GT, Gomes HE, Hickson HS, Hu TMJ, Levine BA, Conlin PR. Web-based care management in patients with poorly controlled diabetes. Diabetes Care 2005 Jul;28(7):1624-1629 [FREE Full text] [Medline: 15983311] 
37. Kempf K, Tankova T, Martin S. ROSSO-in-praxi-international: long-term effects of self-monitoring of blood glucose on glucometabolic control in patients with type 2 diabetes mellitus not treated with insulin. Diabetes Technol Ther 2013 Jan;15(1):89-96. [doi: 10.1089/dia.2012.0213] [Medline: 23194054]

38. Arnhold M, Quade M, Kirch W. Mobile applications for diabetics: a systematic review and expert-based usability evaluation considering the special requirements of diabetes patients age 50 years or older. J Med Internet Res 2014;16(4):e104 [FREE Full text] [doi: 10.2196/jmir.2968] [Medline: 24718852]

39. Shea S, Weinstock RS, Teresi JA, Palmas W, Starren J, Cimino JJ, et al. A randomized trial comparing telemedicine case management with usual care in older, ethnically diverse, medically underserved patients with diabetes mellitus: 5 year results of the IDEATel study. J Am Med Inform Assoc 2009;16(4):446-456 [FREE Full text] [doi: 10.1197/jamia.M3157] [Medline: 19390093]

40. Carter EL, Nunlee-Bland G, Callender C. A patient-centric, provider-assisted diabetes telehealth self-management intervention for urban minorities. Perspect Health Inf Manag 2011;8:1b [FREE Full text] [Medline: 21307985]

41. Stone RA, Sevick MA, Rao RH, Macpherson DS, Cheng C, Kim S, et al. The Diabetes Telemonitoring Study Extension: an exploratory randomized comparison of alternative interventions to maintain glycemic control after withdrawal of diabetes home telemonitoring. J Am Med Inform Assoc 2012;19(6):973-979 [FREE Full text] [doi: 10.1136/amiajnl-2012-000815] [Medline: 22610495]

42. Weitzman ER, Kelemen S, Quinn M, Eggleston EM, Mandl KD. Participatory surveillance of hypoglycemia and harms in an online social network. JAMA Intern Med 2013 Mar 11;173(5):345-351. [doi: 10.1001/jamainternmed.2013.2512] [Medline: 23400234]

43. Gee PM, Greenwood DA, Paterniti DA, Ward D, Miller LM. The eHealth Enhanced Chronic Care Model: a theory derivation approach. J Med Internet Res 2015 Apr;17(4):e86 [FREE Full text] [doi: 10.2196/jmir.4067] [Medline: 25842005]

44. Eysenbach G, Consort- E. CONSORT-EHEALTH: improving and standardizing evaluation reports of Web-based and mobile health interventions. J Med Internet Res 2011;13(4):e126 [FREE Full text] [doi: 10.2196/jmir.1923] [Medline: 22209829]

\section{Abbreviations \\ AADE: American Association of Diabetes Educators \\ ADA: American Diabetes Association \\ CDE: certified diabetes educators \\ DES: Diabetes Empowerment Scale short form \\ DKT: Diabetes Knowledge Test \\ DSMB: Data and Safety Monitoring Board \\ EHR: electronic health record \\ SDSCA: Summary of Diabetes Self-Care Activities \\ SMBG: self-monitoring of blood glucose}

Edited by G Eysenbach; submitted 22.12.14; peer-reviewed by K Pal, K Fitzner; comments to author 12.03.15; revised version received
08.04.15; accepted 24.05.15; published 21.07.15
Please cite as:
Greenwood DA, Blozis SA, Young HM, Nesbitt TS, Quinn CC
Overcoming Clinical Inertia: A Randomized Clinical Trial of a Telehealth Remote Monitoring Intervention Using Paired Glucose
Testing in Adults With Type 2 Diabetes
J Med Internet Res $2015 ; 17(7):$ e178
URL: $\underline{\text { http://www.jmir.org/2015/7/e178/ }}$
doi: $\underline{10.2196 / j m i r .4112}$
PMID: $\underline{26199142}$

(CDeborah A Greenwood, Shelley A Blozis, Heather M Young, Thomas S Nesbitt, Charlene C Quinn. Originally published in the Journal of Medical Internet Research (http://www.jmir.org), 21.07.2015. This is an open-access article distributed under the terms of the Creative Commons Attribution License (http://creativecommons.org/licenses/by/2.0/), which permits unrestricted use, distribution, and reproduction in any medium, provided the original work, first published in the Journal of Medical Internet Research, is properly cited. The complete bibliographic information, a link to the original publication on http://www.jmir.org/, as well as this copyright and license information must be included. 